\title{
Controlled trial of a new cervical spatula
}

\author{
MARGARET R WOLFENDALE， ROMA HOWE-GUEST， MARTIN MCD USHERWOOD, \\ GERALD J DRAPER
}

\begin{abstract}
A wooden spatula was designed to scrape the varied distribution of epithelial abnormalities of the cervix as seen at colposcopy. The efficiency of the spatula in obtaining dyskaryotic cells and improving the cellular quality of smears was compared with that of the Ayre spatula in a controlled trial. More than 17000 smears were taken from women aged 14-86 years by more than 200 smear takers from 74 centres. Twenty two per cent more dyskaryotic smears were obtained with the trial spatula, and the cellular quality of the smears was improved in all age groups. Although it was associated with a slightly increased risk of bleeding, $83 \%$ of users preferred the trial spatula.
\end{abstract}

\section{Introduction}

The difficulty of obtaining accurate samples of the cervix by means of cervical smears has been recognised for many years. Estimates of false negative error rates in patients with severe dysplasia or carcinoma in situ range from $20 \%$ to $45 \%$ and are mainly due to poor sampling. ${ }^{12}$

Since 1944, when Ayre first advocated a spatula for direct sampling of the cervix, ${ }^{3}$ various cervical spatulas of differing shape and material have been developed. ${ }^{2-6}$ Although trials of these spatulas have shown improved detection of endocervical cells, most of the trials have been small, and improved detection of cervical epithelial abnormalities has not been reported.

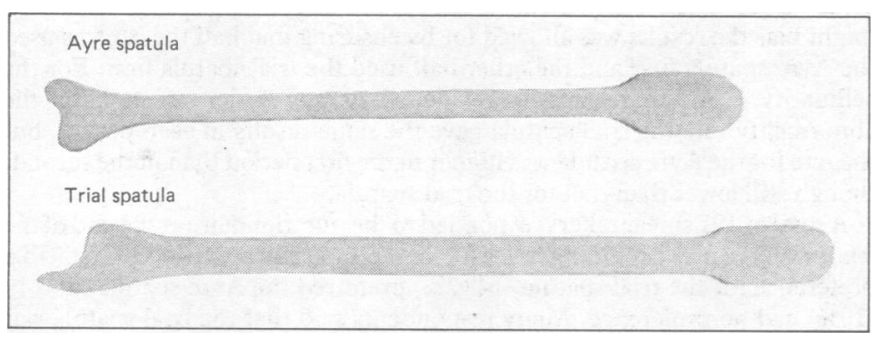

Top: Ayre spatula. Bottom: trial spatula.

The presence of endocervical cells in a smear does not necessarily indicate that a smear was well taken, ${ }^{7}$ and in a retrospective survey of abnormal smears we found that half of the smears containing severely dyskaryotic cells did not contain endocervical cells. For a

\footnotetext{
Departments of Cytology and Obstetrics and Gynaecology, Stoke Mandeville Hospital, Aylesbury HP21 8AL

MARGARET R WOLFENDALE, MB, MD, consultant cytopathologist

ROMA HOWE-GUEST, BA, research assistant

MARTIN MCD USHERWOOD, MB, FRCOG, consultant obstetrician and gynaecologist

Childhood Cancer Research Group, Radcliffe Infirmary, Oxford OX2 6HE GERALD J DRAPER, MA, DPHIL, director

Correspondence to: Dr Margaret R Wolfendale.
}

spatula design to be accepted as an improvement it is essential to show a reduction in false negative sampling.

A profile for a wooden cervical spatula was developed by two of us (MU and MW) based on colposcopic studies of the position of the abnormal epithelium in a wide variety of patients with premalignant and malignant disease of the cervix (figure). The head of the spatula was designed with a projecting end to fit neatly into the external os and extend $1-2 \mathrm{~cm}$ up the endocervical canal. The head was angled to the elongated shaft to enable the spatula to remain applied to a wide area of the endocervix when rotated. The effectiveness of the new spatula was compared with that of the Ayre spatula made of the same type of wood.

\section{Methods}

\section{ORGANISATION OF THE TRIAL}

All those who sent cervical smears to the laboratory were consulted and invited to participate in the trial. For a year before the trial began the cellular content of all smears had been assessed: those with good cellularity including endocervical cells and several streaks of endocervical mucus were graded 1; those with good cellularity, several streaks of endocervical mucus, and usually a few recognisable metaplastic cells were graded 2; and those with inadequate material or which were poorly prepared were graded 3 . The performance of the smear takers from any practice or clinic was assessed as follows: an average score was calculated based on giving an individual score to each smear-a grade 1 smear scoring 1 , a grade 2 smear scoring 0 , and a grade 3 scoring - 1 -and this average score was then multiplied by 100 .

At the start of the trial all centres were told of their score and given the average score for all smear takers for comparison. They were also told that an assessment of the cellular quality would be put at the end of each report for their information. A crossover design was used for the trial, with each centre being randomly allocated to use either the Ayre spatula or the trial spatula for all patients seen during the first period of the trial and then to use the other spatula for the second period. The participants were divided randomly into two groups, A and B. As far as possible good, medium, and poor quality smear takers were divided equally between the two groups. On the basis of previous performances groups $A$ and $B$ were expected to take equal numbers of smears over a given period.

For the first three months group A used the Ayre spatula and group B used the trial spatula. Simple instructions for taking smears were issued with each pack of 12 spatulas. All the old forms and spatulas used before the trial were removed when the trial packs were delivered.

After three months all the unused spatulas were exchanged so that group A had the trial spatulas and group B had the Ayre spatulas. The trial was then continued until each centre had taken roughly the same number of smears with both spatulas. At no time during the trial were any of the staff in the laboratory who were examining the smears told which spatula was allocated to which centre.

\section{ASSESSMENT OF THE EFFECTIVENESS OF THE TRIAL SPATULA}

The main criterion on which the trial spatula was evaluated was the success rate in detecting abnormal cells. A comparison was made of the percentage of smears taken by each spatula which contained dyskaryotic cells suggestive of premalignant or invasive changes. Since the number of abnormal smears taken by gynaecologists may be influenced by other factors such as the number of follow up colposcopy clinics, only smears taken by centres outside hospitals were included in this comparison. We also compared the cellular quality of the smears taken by the two spatulas from all centres using the same criteria and scoring system used before the trial.

At the end of the trial participants were sent a questionnaire asking whether they had a preference for either spatula and inviting their comments on any advantages or disadvantages of the trial spatula. 
In analysing the results we had to allow for the fact that the random allocation of spatulas was applied to centres rather than to individual women, and the outcome to be analysed should therefore be some measure of the effect at each centre rather than the results for individual women. Allowance also had to be made both for the ages of the women from whom the smears were taken and for the crossover design of the trial. Thus comparisons were made between the results for the two types of spatula at each centre, taking the average of the results for each age group within a centre.

For each centre the Ayre and trial spatulas were compared with respect to the two following measures of effectiveness.

Age adjusted cellularity score-An average cellularity score for each type of spatula at each centre was calculated by taking the average score as defined above for each age group, spatula, and centre and forming a weighted average of the results for the different age groups to give an overall score for each type of spatula at each centre, the weights being based on the age distribution of all women included in the study. The difference between the age adjusted cellularity scores for the two spatulas at any centre was an appropriate measure of the difference in the quality of the smears obtained using the two spatulas.

Age adjusted abnormality rate-Similarly, for each centre and spatula the observed rate of dyskaryotic smears was calculated for each age group and a weighted average of these rates was derived. The difference between these age adjusted abnormality rates for the two spatulas was an appropriate measure for comparing the spatulas, allowing for differences in age composition of the groups of women from whom the smears were taken.

\section{Results}

All of the smear takers approached agreed to take part in the trial. There were 37 centres in each group, of which 60 were general practices; 29 were in group A and 31 in group B. They ranged from singlehanded practices to group practices of up to nine doctors, some of which employed a nurse to take the routine smears. The other centres included six consultant gynaecologists, three family planning clinics, two genitourinary medicine clinics, two community health clinics, and one hospital staff clinic.

A total of 17781 smears were included in the trial from patients whose age range was $14-86$ years, most (62\%) being between 20 and 39 years (table I).

TABLE I-Number of smears taken by each group with Ayre spatula and trial spatula according to age of patient

\begin{tabular}{|c|c|c|c|c|c|c|}
\hline \multirow[b]{2}{*}{ Age (years) } & \multicolumn{2}{|c|}{ Group A } & \multicolumn{2}{|c|}{ Group B } & \multicolumn{2}{|c|}{ Total } \\
\hline & Ayre & Trial & Ayre & Trial & Ayre & Trial \\
\hline $\begin{array}{l}<20 \\
20-29 \\
30-39 \\
40-49 \\
50-59 \\
\geqslant 60 \\
\text { Age unknown }\end{array}$ & $\begin{array}{r}241 \\
1158 \\
1499 \\
806 \\
437 \\
176 \\
50\end{array}$ & $\begin{array}{r}280 \\
1175 \\
1290 \\
849 \\
419 \\
169 \\
12\end{array}$ & $\begin{array}{r}302 \\
1523 \\
1438 \\
714 \\
366 \\
234 \\
23\end{array}$ & $\begin{array}{r}240 \\
1341 \\
1492 \\
826 \\
469 \\
220 \\
32\end{array}$ & $\begin{array}{r}543 \\
2681 \\
2937 \\
1520 \\
803 \\
410 \\
73\end{array}$ & $\begin{array}{r}520 \\
2516 \\
2782 \\
1675 \\
888 \\
389 \\
44\end{array}$ \\
\hline Total & 4367 & 4194 & 4600 & 4620 & 8967 & 8814 \\
\hline
\end{tabular}

Slightly fewer smears were taken by group A than by group B, but similar numbers of smears were taken by both groups with each spatula in each 10 year age group. The main exception was that 320 more smears were taken with the Ayre spatula in the group aged 20-39 years and 340 more smears were taken with the trial spatula in women aged 50 and above.

Analysis of the results entailed comparing the two spatulas with respect, firstly, to the cellularity of the smears and, secondly, to the number of abnormalities detected. Table II shows the overall results for the cellularity scores. The comparison of the results for the two spatulas was based on the age adjusted cellularity score. The difference in the scores for the two spatulas was calculated for each centre, and the mean of these differences was used as an overall measure of the difference in effectiveness of the spatulas. This mean was significantly different from zero $(p<0.001, t$ test, $72 \mathrm{df}$ ), and there is therefore convincing evidence that the quality of the smears obtained with the trial spatula was better than that of smears taken with the Ayre spatula. For $55(74 \%)$ of the 74 centres the results were better with the trial spatula.

Table III shows the overall results for the detection of dyskaryotic smears, excluding those taken in hospital clinics (for reasons given above). The difference between the percentage detection rates, allowing for the effects of age, was significant $\left(p<0.02, \chi^{2}\right.$ test). This test, however, does not take into account the fact that a form of group randomisation was used and that the appropriate analysis should actually be based on the age adjustect abnormality rate for each centre, referred to above. The trial spatulad performed better than the Ayre spatula in 39 centres, the Ayre was better in 25 centres, and no abnormalities were detected in four centres. Though not statistically significant, taken in conjunction with the results given above, this difference strongly suggests that the trial spatula gives a better detection rate than the Ayre spatula.

TABLE II-Comparison of scores for cellular quality for Ayre spatula and trial spatule

\begin{tabular}{lcclcc}
\hline & \multicolumn{2}{c}{ Group A } & & \multicolumn{2}{c}{ Group B } \\
\cline { 2 - 3 } \cline { 5 - 6 } $\begin{array}{l}\text { Age group } \\
\text { (years) }\end{array}$ & Ayre & Trial & & Ayre & Trial \\
\hline$<20$ & $28 \cdot 2$ & $33 \cdot 2$ & & $23 \cdot 5$ & $29 \cdot 6$ \\
$20-29$ & $32 \cdot 6$ & $37 \cdot 1$ & & $29 \cdot 6$ & $37 \cdot 9$ \\
$30-39$ & $33 \cdot 6$ & $45 \cdot 6$ & & $30 \cdot 0$ & $36 \cdot 4$ \\
$40-49$ & $28 \cdot 3$ & $44 \cdot 9$ & & $26 \cdot 0$ & $46 \cdot 2$ \\
$50-59$ & $18 \cdot 9$ & $31 \cdot 8$ & & $15 \cdot 6$ & $22 \cdot 6$ \\
$\geqslant 60$ & $7 \cdot 4$ & $9 \cdot 4$ & & $3 \cdot 0$ & $7 \cdot 3$ \\
All ages & $29 \cdot 7$ & $39 \cdot 4$ & & $26 \cdot 4$ & $34 \cdot 2$ \\
\hline
\end{tabular}

TABLE III-Comparison of detection rate of dyskaryotic smears by Ayre spatula and trial spatula. Results are numbers and percentages

\begin{tabular}{lrr}
\hline Age group (years) & \multicolumn{1}{c}{ Ayre } & \multicolumn{1}{c}{ Trial } \\
\hline$<20$ & $13(2 \cdot 7)$ & $16(3 \cdot 4)$ \\
$20-29$ & $102(4 \cdot 3)$ & $117(5 \cdot 1)$ \\
$30-39$ & $83(3 \cdot 2)$ & $100(4 \cdot 0)$ \\
$40-49$ & $23(1 \cdot 7)$ & $32(2 \cdot 1)$ \\
$50-59$ & $6(0 \cdot 8)$ & $11(1 \cdot 3)$ \\
$\geqslant 60$ & $1(0 \cdot 3)$ & $3(0 \cdot 9)$ \\
All ages & $228(2 \cdot 9)$ & $279(3 \cdot 5)$ \\
& & \\
\hline
\end{tabular}

In designing the trial we had to allow for the possibility of an "ordero effect"- that is, that smears taken in the first half of the trial might differ in some way from those taken during the second half. The possibility that this $\overrightarrow{\bar{A}}$ might bias the results was allowed for by ensuring that half the centres used 3 the Ayre spatula first and the other half used the trial spatula first. For the cellularity score there was no evidence of any order effect. For the्ठ abnormality rate the trial spatula gave the same results in each period, but the rate for the Ayre spatula was higher in the first period than in the second, though still lower than that for the trial spatula.

A total of 197 smear takers responded to the questionnaire at the end of theo trial, every centre providing at least one reply. Of these, $164(83 \%)$ stated a preference for the trial spatula, $14(7 \%)$ preferred the Ayre spatula, and 190 $(10 \%)$ had no preference. Many respondents said that the trial spatula was -3 easier to use and they thought they took better smears with it. Twenty four (12\%) smear takers noted a slightly greater tendency for the trial spatula tocause mild bleeding.

\section{Discussion}

The sampling error in cervical smears is difficult to determine ${ }_{\sigma}^{\omega}$ precisely, but in our laboratory it was thought to be about $20 \%$ before the trial. The trial spatula detected $22 \%$ more smears with dyskaryotic cells than the Ayre spatula, the effect being seen in allos age groups. No bias could be introduced by the reporting of dyskaryotic smears in the laboratory as those screening ando reporting the smears did not know which spatula was being used and they remained in post throughout the trial.

Examination of the results in more detail showed that there were significantly more minor abnormalities - that is, borderline or atypical cells (3.0\% compared with $2 \cdot 5 \%$ of all smears) -in smearso taken by the Ayre spatula. On the other hand there was a relativelys greater increase in the diagnosis of cervical intraepithelial neoplasiac (CIN) III lesions $(0.8 \% v 1 \cdot 1 \%)$ compared with CIN I and CIN II ${ }^{+}$ 
lesions $(2 \cdot 1 v 2 \cdot 4 \%)$ with the trial spatula. The improvement in the cellular quality of the smears with the trial spatula would therefore seem to be a reflection of more accurate sampling. It is also encouraging to note that this improvement in cellular quality was particularly striking in the $40-59$ year age group, in which there is a comparatively large proportion of unscreened women whom we hope, with the current national emphasis on the importance of screening, will be screened in the near future.

In $26 \%$ of the centres the quality of smears taken did not improve, but no information was obtained on the number of smears taken by individuals in each centre and these could have varied considerably during the trial. Also these centres tended to have the better smear takers with both spatulas.

The trial spatula was used by a wide cross section of smear takers on women from a wide age range, and at the end of the trial 164 $(83 \%)$ of 197 smear takers who responded to a questionnaire stated a preference for the trial spatula. Twenty four $(12 \cdot 2 \%)$ of the respondents reported bleeding after use of the trial spatula, and in a few patients in whom the os was tight or stenosed the tip of the spatula could not be inserted. In these cases the use of a brush may be indicated. Occasionally the blood staining made a smear difficult to examine, which may partially account for the lack of a significant reduction in the numbers of unsatisfactory smears taken by the trial spatula. The other problem encountered in screening was that the larger number of endocervical cells increased the number of smears referred for checking since at times it can be difficult to distinguish between inflamed endocervical cells and dyskaryotic endocervical cells or carcinoma in situ from the endocervical crypts.

In conclusion, the advantages of easier and better sampling of the cervix by the trial spatula far outweighed any minor problems, and we recommend that the new spatula should be seriously considered for use for cervical screening on a national basis.

We thank Marks and Spencer plc for its financial support of the trial and the Bucks Herald newspaper, who raised the money for the fund from which the spatula was purchased. We also thank David Corney, who helped with computing; Dr O A N Husain for his advice and support; all our colleagues who helped assess the prototype models of the spatula; and the many colleagues who participated in the trial. We acknowledge the help of Professor G P Vooijs, Nijmegen, who sent us a sample of his ideal spatula after we had designed our own. GJD is supported by the Department of Health and Social Security and the Scottish Home Health Department.

The spatula is available from Histopath Ltd, PO Box 101, Hemel Hempstead, Herts.

\section{References}

1 Husain OAN, Butler EB, Evans DM, et al. Quality control in cervical cytology. $\mathcal{J}$ Clin Pathol 1974;27:935-44.

2 Beilby JOW, Bourne R, Guillebaud J, Steele ST. Paired cervical smears: a method of reducing the false negative rate in population screening. Obstet Gynecol 1982;60:46-8.

3 Ayre JE. A simple office test for uterine cancer diagnosis. Can Med Assoc $\mathcal{J}$ 1944;51:17-22.

4 Colon VF. The extended tip spatula for cervical cytology. $f$ F am Pract 1981;13:37-41.

5 Bounds W, Grubb C, Metaxas N, Vessey M. A randomized comparative trial of the performance of the Ayre and the Armovical cervical spatulae. Br $f$ Obstet Gynaecol 1976;83:981-7.

6 House FR, Shepherd JM, Vale JC. The Multispatula: a new dimension in sampling the cervix. Lancet 1984; i:1214-5.

7 Koss LG, Hicklin MD. Standards of adequacy of cytologic examination of the female genital tract. Conclusions of a study group on cytology. Obstet Gynecol 1974;43:792-4.

(Accepted 28 October 1986)

\section{Waiting for the drop}

The other day I heard on the radio a motoring flash about traffic congestion at Gallows Corner. It took me back over 40 years to Sunday 4 June 1944, when our convoy was snarled up at this particular junction, en route to our embarkation port for what the military handbook had euphemistically described as a "short sea voyage".

I had ample time while stuck in that traffic jam to ponder on and confirm the truth of Dr Johnson's dictum that the prospect of being hanged concentrated a man's mind wonderfully. It certainly did that for me, as my sins of omission and commission flashed past like a modern "action replay."

We were subsequently given Monty's stirring message, including the "words of a famous soldier, spoken many years ago":

He either fears his fate too much Or his deserts are small,

Who dare not put it to the touch

To win or lose it all.

I had no idea, then, who the famous soldier was or of the circumstances of his poem. It was only after the war that I discovered that the author was James Graham, Marquis of Montrose (1612-50), and that the poem was written on the window of his gaol the night before he was hanged.- $R A$ STRANG, Wembley, Middlesex.

\section{Stormy weather for the new technology}

There we were sitting in the aircraft that was to take us from Chicago's O'Hare airport to Manchester, with rain pelting down and flashes of lightning illuminating the darkening sky. The door was closed, and we sat, and sat . . 20 minutes later came the disembodied voice of the stewardess: "I'm sorry, there is a malfunction of the windshield heater. We have an engineer working on it and it should take about 20 minutes."

Two hours later, with the storm still raging (and thoughts that O'Hare was the setting for that memorable film Airport), we disembarked with the promise that soon another aircraft would be brought from the hangar. But 'twas not to be. "Flight cancelled" was the next announcement. "You will all be rebooked for tomorrow night." So off we trooped to the airport hotel (courtesy of American Airlines), booked in, and went to our room, or what should have been our room-but when I put the key in the door (it was now $1 \mathrm{am}$ ) there was a scurrying on the other side and the door opened to reveal another couple, fortunately not yet in bed.

"I think you are in the wrong room," I stammered, showing the key.

"Snap," he said, showing me one with the identical number.

So, somewhat aggrieved and weary, back we went to reception to find that the storm had "put down" the hotel computer, so that they did not know which rooms were occupied and which were not. It all had to be sorted out manually. Which gave me considerable food for thought when we eventually went to bed and I lay awake thinking of the forthcoming computerisation of our $x$ ray departments. . . - MYER GOLDMAN, consultant radiologist, Liverpool.

\section{Nor all that glisters...}

As we entered Bendigo the coach driver told us over the intercom that round the next bend we should see the new American embassy on the right hand side of the street-it turned out to be a MacDonald's takeaway.

In Bendigo they have preserved the gold mine, which was the last to function in the state of Victoria, finally closing in the 1950s. The miners who worked underground in the early days of the mine's existence had a working life of about five years-the time it took for their lungs to become choked with dust.

The goldbearing rock is raised to the surface and then crushed, and the resultant particles are riddled through a mesh impregnated with mercury to which the gold becomes attached while the crushed remains of the rock fall through. Subsequent heating of the mixture of gold and mercury separates the two metals.

Precautions against theft of the gold by the mine workers were strict and mostly effective. One miner, however, had the idea that as it was too risky to try to steal any gold he might instead have a go at the mercury, which was also of considerable value. To this end he made a hole in the frame of his bicycle and when the opportunity arose surreptitiously poured mercury into it. The scheme worked well until one day he accidentally dropped his bicycle when wheeling it through the checkout and was seen to be having considerable difficulty in lifting it-and so all was revealed.

Another case of man's inability to overcome the effects of gravity?ROBERT HOUSE, retired general practitioner, Tewkesbury. 